of type III procollagen (PIIIP) correlate with the activity of fibrogenesis, although values are influenced by the degree of hepatic inflammation. This assay is therefore of only limited value during the acute phase of alcoholic liver disease or viral hepatitis ${ }^{17}$ and is no use in children since the high PIIIP values attributable to growth in small children greatly exceed those found in liver disease. ${ }^{18}$ Serum laminin P1 reflects basement membrane turnover and correlates with portal venous pressure in fibrotic liver diseases. ${ }^{19}$ Other potentially useful markers are currently being evaluated. Although the gold standard remains liver biopsy, these serological tests allow fibrogenesis to be monitored over time and may be useful in evaluating new and existing antifibrotic treatments.

Although many drugs used in managing chronic liver disease interfere with the synthesis of matrix proteins - for example, corticosteroids, colchicine, and penicillaminetheir application has been largely empirical. A greater understanding of the mechanisms of fibrogenesis has stimulated the development of more rational approaches. The most promising of these are inhibitors of prolyl 4-hydroxylase, a key enzyme in the biosynthesis of collagen. Identifying compounds which can act as inhibitors only after biotransformation by liver specific enzymes offers an exciting prospect of tissue specific antifibrotic activity. ${ }^{20}$ Other options include manipulating the retinoid content of perisinusoidal cells, ${ }^{21}$ TGF $\alpha$ and TGF $\beta$ antagonists, and compounds which either stimulate interstitial collagenase production or decrease TIMP-1 synthesis. A more speculative but exciting development is of agents which specifically interfere with matrix gene transcription or translation such as antisense RNA. ${ }^{22}$

ALASTAIR D BURT

Senior Lecturer in Pathology,

School of Pathological Sciences,

University of Newcastle upon Tyne,

Newcastle upon Tyne NE1 4LP
Schaffner F, Sieratzki JS. The early history of cirrhosis. In: Boyer JL, Bianchi L, eds. Liver cirrhosis. Lancaster: MTP Press, 1987:57-62.

2 Schuppan D, Somasundaram $\mathbf{R}$, Just $M$. The extracellular matrix: a major signal transduction network. In: Clément B, Guillouzo A, eds. Cellular and molecular aspects of cirrhosis. INSERM/J Libbey, 1992:115-34.

3 Volpes R, Van den Oord JJ, Desmet VJ. Distribution of the VLA family of integrins in normal and pathological human liver tissue. Gastroenterology 1991;101:200-6.

4 Arthur MJP. Matrix degradation in the liver. Semin Liver Dis 1990;10:47-55.

5 Arthur MJP, Iredale JP, Murphy G, Humbry RM, Friedman SL. Human hepatic lipocytes synthesize and release TIMP-1, an important regulator of matrix metalloproteinase activity. Hepatology 1991;14:183A.

6 Geerts A, Vrijsen R, Burt A, Schellinck P, Wisse E. In vitro differentiation of fat-storing cells parallels marked increase of collagen increase and secretion. $f$ Hepatol 1989;9:59-68.

Friedman SL Cellular sources of collagen and regulation of collagen production in liver. Semin Liver Dis 1990:10:20-9.

8 Burt AD, Griffiths MR, Schuppan D, Voss B, MacSween RNM. Ultrastructural localization of extracellular matrix proteins in human liver biopsies using ultracryomicrotomy and immunogold labelling. Histopathology 1990;16:53-8.

9 Milani S, Herbst H, Schuppan D, Hahn E, Stein H. In situ hybridization for procollagen types I, III and IV mRNA in normal and fibrotic rat liver: evidence for predominant expression in nonparenchymal cells. Hepatology 1989;10:84-92.

10 Clément B, Rescan PY, Baffet G, Loréal O, Lehry D, Campion JP, et al. Hepatocytes may produce laminin in fibrotic liver and in primary culture. Hepatology 1988;8:794-803.

11 Blomhoff $\mathrm{R}$, Wake $\mathrm{K}$. Perisinusoidal stellate cells of the liver: important roles in retinol metabolism and fibrosis. FASEB 7 1991;5:271-7.

12 Geerts A, Lazou J-M, De Bleser P, Wisse E. Tissue distribution, quantitation and proliferation kinetics of fat-storing cells in carbon tetrachloride-injured rat liver. Hepatology 1991;13: 1193-202

13 Tanaka AY, Nouchi T, Yamane M, Irie T, Miyakaw H, Sato O, et al. Phenotypic modulation of lipocytes in experimental liver fibrosis. $\mathcal{F}$ Pathol 1991;164:273-8.

14 Johnson SJ, Hillan KJ, Hines JE, Ferrier R, Burt AD. Proliferation and phenotypic modulation of perisinusoidal (Ito) cells following acute liver injury: temporal relationship with TGF $B_{1}$ pexpression. In: Clement B, Guillowzo A, eds. Cellular and Molecular Aspects of Cimhosis. INSERM/J Libbey, 1992:219-22.

15 Gressner AM, Bachem MG. Cellular sources of noncollagenous matrix proteins: role of fat-storing cells in fibrogenesis. Semin Liver Dis 1990;10:30-46.

16 Casini A, Cunningham M, Rojkind M, Lieber CS. Acetaldehyde increases procollagen type I and fibronectin gene transcription in cultured rat fat-storing cells through a protein synthesisdependent mechanism. Hepatology 1991;13:758-65.

17 Schuppan D. Connective tissue polypeptides in serum as parameters to monitor antifibrotic treatment in hepatic fibrogenesis. I Hepatol 1991;13:S17-S25.

18 Triveldi P, Cheeseman P, Portmann B, Mowat AP. Serum type III procollagen propeptide as a noninvasive marker of liver damage during infancy and childhood in extrahepatic biliary atresia, idiopathic hepatitis of infancy and $\alpha 1$ antitrypsin deficiency. Clin Chim Acta 1985;161:137-46.

19 Gressner AM, Titton W, Negwer A, Pick-Kober KH. Serum concentrations of laminin and aminoterminal propeptide of type III procollagen in relation to the portal venous pressure of fibrotic liver diseases. Clin Chim Acta 1986;161:249-58.

20 Bichel M, Baader E, Brocks DG, Engelbart K, Günzler V, Schmidts HL, et al. Beneficial effects of inhibitors of prolyl 4-hydroxylase in $\mathrm{CCl}_{4}$-induced fibrosis of the liver in rats. $f$ Hepatol 1991;13:S26-S34

21 Pinzani $M$, Paolo G, Abboud HE. Phenotypical modulation of liver fat-storing cells by retinoids. Influence on unstimulated and growth factor-induced cell proliferation. $f$ Hepatol 1992;14: $211-20$

22 Chojkier M, Brenner DA. Therapeutic strategies for hepatic fibrosis. Hepatology 1988;8:176-82.
Unexpected sudden death in fit young people is distressing; but if the death is explicable the family may be able to begin the process of psychological adjustment. The pathologist has, then, an obligation to explain the death and should follow a logical approach.

Firstly, unnatural death has to be excluded, largely on the basis of the investigation by the coroner's officers. Misuse of solvents or cocaine, for example, is associated with sudden death.

Secondly, extracardiac causes are excluded. Thirdly, the heart is examined for conditions associated with sudden death. Between the ages of 40 and 69 coronary atherosclerosis is the cause of $65 \%$ of sudden deaths in men and $40 \%$ in women. ${ }^{1}$ Coronary atherosclerosis is a rare direct cause of death in younger age groups, but pathologists do see coronary thrombosis in the third decade. Pathologists need to draw a distinction between the presence of atherosclerosis, which is virtually universal in Western populations from an early age, and coronary heart disease as a cause of death. Further evidence is required for their diagnosis - high grade stenosis, thrombosis, or old or recent infarction.

Several other cardiac conditions are known to be associated with sudden death. Hypertrophic cardiomyopathy is still underdiagnosed at necropsy owing to its protean macroscopic appearances. ${ }^{3}$ The diagnosis must be excluded positively by histological examination. Right ventricular dysplasia is another familial cardiomyopathy strikingly associated with death on exercise in fit people. ${ }^{45}$ The fully developed condition, in which the right ventricular wall is totally replaced by fat and fibrous tissue, is easily recognised. Study of affected families has shown, however, that sudden death can occur at an earlier stage, when recognition at necropsy is difficult.

Left ventricular hypertrophy of more than $50 \%$ by mass is associated with sudden death in its own right. Furthermore, histological examination of the myocardium should be undertaken in all cases to exclude myocarditis and fibrosis as causes of arrhythmias.

Abnormalities of the coronary. arteries associated with sudden death include one ostium arising in the pulmonary artery ${ }^{6}$ and spontaneous dissection of a coronary artery, which occurs much more commonly in women than men. ${ }^{7}$

A small subset of patients with prolapse of the mitral valve have palpitations and may die suddenly. ${ }^{89}$ Given the total number of people with mitral prolapse, the risk must be very low, but if no other cause of death is found at necropsy the 
probability that the valve lesion caused death is high.

Finally, what is to be done when the heart is morphologically normal and there is no apparent cause of death? In many such cases the probable cause is a cardiac arrhythmia resulting from physiological rather than anatomical abnormalities. Electrocardiographic abnormalities - a long QT interval and pre-excitation (Wolff-Parkinson-White syndrome)-are associated with sudden death; but if death occurs in someone who has not had electrocardiography the heart will be apparently normal at necropsy and no cause of death will be found. Right ventricular tachycardias are also associated with sudden death; the heart may appear normal or have varying degrees of fibrous scarring. ${ }^{+}$

When inquiries are made about people who have dropped dead without cause many will be found to have had previous episodes of syncope or palpitations, or both. Some may have been suspected of having petit mal. The distinction between syncope induced by an arrhythmia and minor epilepsy is often difficult in life and may not be resolved at necropsy. After grand mal seizures have been excluded there is still an excess of sudden death in people with epilepsy. ${ }^{111}$

Coronary artery spasm is a potential cause of acute myocardial ischaemia and thus sudden death. ${ }^{12}$ The combination of a history of chest pain and normal arteries at necropsy may point to the diagnosis.

When all these diagnoses have been considered there will still be some people with no history of chest pain, palpitations, or syncope and no cause of death shown by the most careful necropsy. The size of this problem in Britain is not known because there is no agreed nomenclature for categorising and recording the cases. Sudden death without apparent cause during sleep at night has a particularly high incidence in some migrant Asian communities worldwide. ${ }^{131+}$

Some coroners in England and Wales accept a diagnosis of "natural death-cause unascertained"; others do not. A pathologist may be tempted erroneously to ascribe death to ischaemic heart disease. Another temptation is to find minor abnormalities of the conduction system. ${ }^{15}$ The proof that abnormalities such as nodoventricular connections cause death is tenuous because they may also be found in the hearts of young people who have died accidentally. A similar difficulty arises with myocardial bridging, in which an epicardial coronary artery is covered by an external layer of myocardium. In some well documented clinical cases compression of the artery has been shown to cause ischaemia, but to ascribe death to bridging is difficult because of the frequency of the finding in control hearts. ${ }^{16}$

It would help bereaved families - and scientific knowlegeif a category of sudden unexpected death syndrome was recognised. Many pathologists and coroners have arrived at this sensible point by mutual agreement. There are certain analogies with the sudden infant death syndrome. Both conditions are probably heterogeneous, and in both necropsy does not explain the cause of death. The existence of the category sudden infant death syndrome has, however, not only helped research but also given families a feeling that they understand, and can begin to accept, the death.

M J DAVIES

Professor,

St George's Hospital Medical School,

London SW17 0RE

1 Thomas AC, Knapman PA; Krikler DM, Davies MJ. Community study of the causes of "natural" sudden death. BMF 1988;297:1453-6.

Davies MJ. Anatomic features in victims of sudden coronary death. Circulation 1992;85:19-24

3 McKenna WJ, Camm AJC. Sudden death in hypertrophic cardiomyopathy-assessment of patients at high risk. Circulation 1989:80:1489-92.

4 Fontaine G, Frank R, Fontaliran F, Lascault G, Tonet J. Right ventricular tachycardias. In: Parmley WW, Chatterjee K, eds. Cardiology. Vol 1. Philadelphia: J B Lippincott, 1992:1-17.

Corrado D, Thiene G, Nava A, Rossi L, Pennelli N. Sudden death in young competitive athletes: clinicopathological correlations in 22 cases. Am 7 Med 1990;89:588-96.

6 Lipsett J, Byard RW', Carpenter BF, Jimenez CL, Bourne AJ. Anomalous coronary arteries arising from the aorta associated with sudden death in infancy and childhood. Arch Pathol Lab Med

Mathieu D, Larde D, Vasile N. Primary dissecting aneurysm of the coronary arteries: case report and literature review. Cardiovasc Intervent Radiol 1984;7:71-4.

Boudoulas H, Kligfield P, Wooley CF. Mitral valve prolapse: sudden death. In: Boudoulas H, Wooley CF, ed. Mitral valve prolapse and the mitral valve prolapse syndrome. Mount Kisco, NY: Futura, 1988:591-605.

9 Kligfield P, Devereux RB. Is the mitral valve prolapse patient at high risk of sudden death identifiable? Cardiovasc Clin 1990;21:143-60.

10 Jay GW, Leestrama JE. Sudden death in epilepsy: a comprehensive review of the literature and proposed mechanisms. Acta Neurol Scand [Suppl] 1981;82:63-6.

11 Brown SW, Mawer GE, Lawler W, Taylor DC, Shorvon S, Betts TA, et al. Sudden death and epilepsy. Lancet 1990;335:606-7.

12 Myerburg RJ, Kessler KM, Mallon SM, Cox MM, de Marchene E, Interian A, et al. Life threatening arrhythmias in patients with silent myocardial ischemia due to coronary artery
spasm. $N$ Engl f Med 1992;326:1451-5.

13 Kirscher RH, Eckner FAO, Baron RC. The cardiac pathology of sudden unexplained death in South East Asian refugees. fAMA 1986;256:2700-5.

14 Goh KT, Chao TC, Chew CH. Sudden nocturnal death (SUND) among Thai construction workers in Singapore. Lancet 1990;335:1154-5.

15 Bharati $S$, Lev $M$. Congenital abnormalities of the conduction system in sudden death in young adults. F Am Coll Cardiol 1986;8:1096-104.

16 Ferreira AG, Trotter SE, Konig B, Decourt LV, Fox K, Olsen EGJ. Myocardial bridges: morphological and functional aspects. Br Heart $\mathcal{F} 1991 ; 66: 364-7$.

\title{
Reducing aortocaval compression: how much tilt is enough?
}

\author{
Do as much as possible in the lateral position
}

During late pregnancy the mother's adoption of the supine position allows the uterus to compress her aorta and vena cava. Such compression may produce potentially adverse physiological disturbances in both the mother and the fetus. Although initially thought to be a problem confined to the recumbent position, aortocaval compression has now also been shown in standing ${ }^{1}$ and semirecumbent ${ }^{2}$ positions. The effects of such compression are exacerbated during regional anaesthesia and labour. Obstetricians have traditionally sought to reduce these disturbances by tilting the mother away from the supine position, but is the amount of tilt traditionally used enough?

Around a tenth of women spontaneously develop the supine hypotensive syndrome or "revealed caval compres- sion." In others supine compression of the vena cava is concealed since there is no change in maternal blood pressure ${ }^{34}$ and only a small decrease in cardiac output. ${ }^{+}$These women, however, remain more susceptible to hypotension from factors that impair normal circulatory control. The sympathetic blockade of regional anaesthesia prevents reflex venoconstriction and augments the deleterious effects of venous obstruction on cardiac output. Compression of the vena cava also makes maternal resuscitation from cardiac arrest much more difficult, and it may actually increase the fraction of intravenous bupivacaine delivered to the myocardium. $^{5}$

The fetus too is at risk of reduced oxygen delivery during supine aortocaval compression because of decreased utero- 